\title{
Equal Channel Angular Pressing: A Novel Technique for the Production of Ultra Fine Grained Structure in Materials- A Mini Review
}

\author{
S. Senthil Murugan \\ Assistant Professor \\ Department of Mechanical Engineering \\ Mepco Schlenk Engineering College, India
}

\begin{abstract}
Equal Channel Angular Pressing (ECAP) is an emerging metal forming technique and a potential tool for producing submicron level grain structured materials without substantial change in their cross section by pure shear. ECAP is one of the most important mechanical processing methods used to convert coarse grain metals, alloys and composites into ultrafine grained (UFG) and bulk nano-structured materials, leading to higher mechanical properties compared to the existing secondary processing methods. Grain refinement and texture modification by ECAP can improve the forming characteristics of material. This paper is to give the awareness of ECAP among researchers and the basic ideas about the ECAP principle, die angles, recent development towards research and various processing routes of ECAP. The materials processed by ECAP are widely used in aerospace, automobile, energy applications etc...
\end{abstract}

Keywords: UFG, ECAP, SRS, processing routes, die angles.

\section{INTRODUCTION}

Ultra fine grained (UFG) materials having a grain size of hundred nanometers to one micrometer exhibit an enhanced strength and sometimes also an enhanced ductility. All UFG microstructures exhibit strongly increased strain rate sensitivity (SRS) compared to the conventional grain sized (CG) state. The strain rate increases with increasing temperature and is more pronounced for the UFG material processed using equal channel angular pressing (ECAP) passes [1]. Enhanced SRS can be considered as one of the relevant effects, which are responsible for the enhanced ductility, since necking will be prevented by elevated SRS. For successful rate of UFG metals in technological applications it is necessary to understand the deformation behavior of the new materials in details. It is theoretically possible to achieve super plasticity at low temperatures and or high strain rates by reducing grain size of metallic materials [2]. These grain refinement leads to considerable increases in tensile strength, hardness corrosion and wear resistance in comparison to coarse grained counterparts [3]. Numerical investigations of ECAP show that it is necessary to process materials by ECAP up to multiple passes in order to achieve satisfactory UFG microstructures [4].

\subsection{Equal Channel Angular Pressing}

It is an effective fabrication process for obtaining ultrafine grained materials. ECAP was first introduced is forming process in which high strain is imposed into the metal by simple shear. It has become an important processing procedure for refining microstructure in metallic materials through severe plastic deformation (SPD) process [5]. Good homogeneity may be achieved through ECAP processing when the number of passes in ECAP reasonably high. The extent of homogeneity attained in ECAP depends on the hardening characteristics of the material. ECAP process can be used to produce semi-finish profile products. ECAP produces samples that are large enough for valid testing and determination of fatigue crack growth behavior. The ECAP gives lower quality materials, but still good enough for further process. Processing by ECAP leads to significant strengthening of the material at ambient temperature and provided the ultrafine grains have a reasonable thermal stability, to the occurrence of super plastic ductility at high strain rates and at elevated temperature. To attain equi-axed grain refinement with maximum mechanical properties at least the sample has to be pressed for four passes so it can be achieved only through solution treated and annealed conditions samples. 


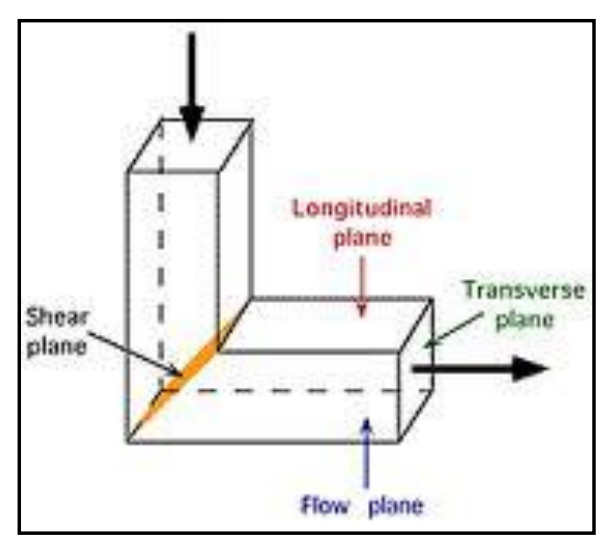

(a)

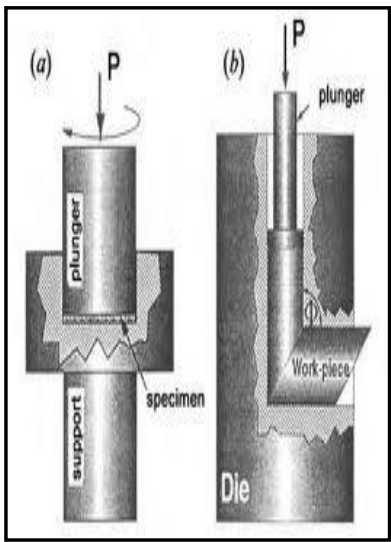

(b)

Figure 1: ECAP principle

\subsection{Principle of ECAP}

Figure $1(\mathrm{a}, \mathrm{b})$ shows the ECAP principle. In this process, a rod is pressed through a die constrained within a channel which is bent through an abrupt angle ' $\Phi$ ', and with a corner curvature angle ' $\psi$ '. Under ideal conditions, it is confirmed that a sample pressed through an ECAP die will undergo a homogeneous simple shear strain. But the applied strain during ECAP is not homogeneous. Because there is a frictional force between the sample and the die wall and this may change the strain distribution in the vicinity of the die walls. Shear strain is applied to the sample along a sharp and well-defined shear plane (figure 1a) lying at $45^{\circ}$ with respect to the $\mathrm{x}$-axis and corresponding to the abrupt transition between the two parts of the channel. The main factors influencing during ECAP process are Pressing temperature, and Pressing load \& speed.

\subsection{Influence of Die Angles in ECAP Dies}

The main factors which influence the homogeneity include the die corner angle within the ECAP die and number of imposed passes. It is well established that the strain achieved through a single pass of ECAP is related only to the die angles ' $\Phi$ ' and ' $\psi$ ' under ideal conditions. Channel angle of $\Phi=90^{\circ}$ is maintained because it is most effective angle in achieving an ultrafine grained microstructure. There are two different ECAP facilities one is a solid die made of tool steel with the channels having circular cross section and $\psi=20^{\circ}$. And the other one is a split die consists of two parts with a square cross section of $\psi=0^{\circ}$. The die angles are explained here in the figure 2 shows the 3D view of ECAP die with and without pressed samples and two dimensional view of die angles.

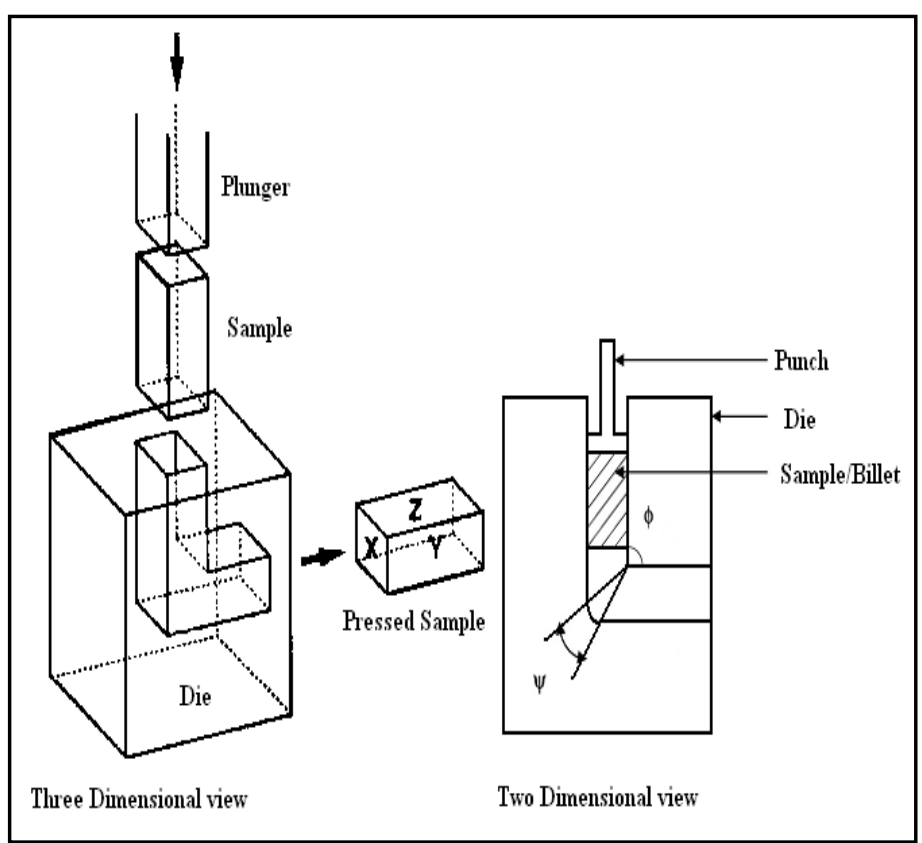

Figure2. ECAP die with sample \& die angles 
It is well established that the use of an ECAP die with a sharp corner having an arc of curvature of $\psi=0^{\circ}$ leads to the occurrence of a "dead zone" at this outer corner where the billet is no longer in contact with the die wall. The problems associated with these dead zones can be removed through the use of dies having movable die walls. The inhomogeneous layer covers a slightly larger area in the sample pressed using a sharp corner die with $\psi=0^{\circ}$ rather than when using a die with $\psi=20^{\circ}$. Then $\psi=20^{\circ}$ introduces no additional in homogeneity into the sample during the ECAP process.

Total strain accumulated in work piece after $\mathrm{N}$ passes through ECAP die is given by the equation 1 .

$$
\varepsilon_{\mathrm{D}}=\frac{N}{\sqrt{3}}\left[2 \cot \left(\frac{\Phi}{2}+\frac{\Psi}{2}\right)+\Psi \operatorname{cosec}\left(\frac{\Phi}{2}+\frac{\Psi}{2}\right)\right]
$$

Where, $\mathrm{N}=1$. $\varepsilon$-Strain, $\Phi$-channel angle, $\Psi$ - angle of the arc of curvature

At the same time, a sharp corner die is preferable to a round corner die in producing a homogeneous shear strain distribution over the cross sectional plane. Some investigations show that a round corner die with $\psi=28^{\circ}$ tends to produce a more homogeneous structure. The use of a solid die leads to a more convenient and efficient pressing procedure because it avoids the problems associated with the extrusion of slivers of material between the two parts of the die. Therefore using a solid die with an internal angle of $\psi=20^{\circ}$ appears to be an excellent choice when developing a facility for ECAP processing.

\subsection{ECAP Processing Routes}

Figure 3 shows the various processing routes for aluminum available in ECAP. The success of ECAP technique leads to concerns and interest in the development of homogeneity. It is necessary to process materials by ECAP up to multiple passes in order to achieve satisfactory ultrafine grained microstructure. Materials initially become in homogeneous after a single pass of ECAP but thereafter they evolve so that there is the development of a homogenous microstructure with increasing numbers of passes except only in a very small area in the vicinity of the bottom surface. It is found that after four ECAP passes via. routes $\mathrm{A}, \mathrm{B}_{\mathrm{A}}, \mathrm{B}_{\mathrm{C}}, \mathrm{C}$, the microstructure of aluminum becomes relatively homogeneous [6], they represent situations in which the sample is not rotated between passes (route A), rotated by $90^{\circ}$ in alternate directions between each pass (route $\mathrm{B}_{\mathrm{A}}$ ), rotated by $90^{\circ}$ in the same sense between passes (route $\mathrm{B}_{\mathrm{C}}$ ) and rotated by $180^{\circ}$ between passes (route C). Multiple passes through the die are possible without any reduction in cross-sectional area. For each route the shape of the cube is illustrated separately for the $\mathrm{X}, \mathrm{Y}$ and $\mathrm{Z}$ planes (in figure 2). It is found experimentally that route $\mathrm{B}_{\mathrm{C}}$ is the optimum processing route in order to achieve a homogeneous array of ultrafine grains.

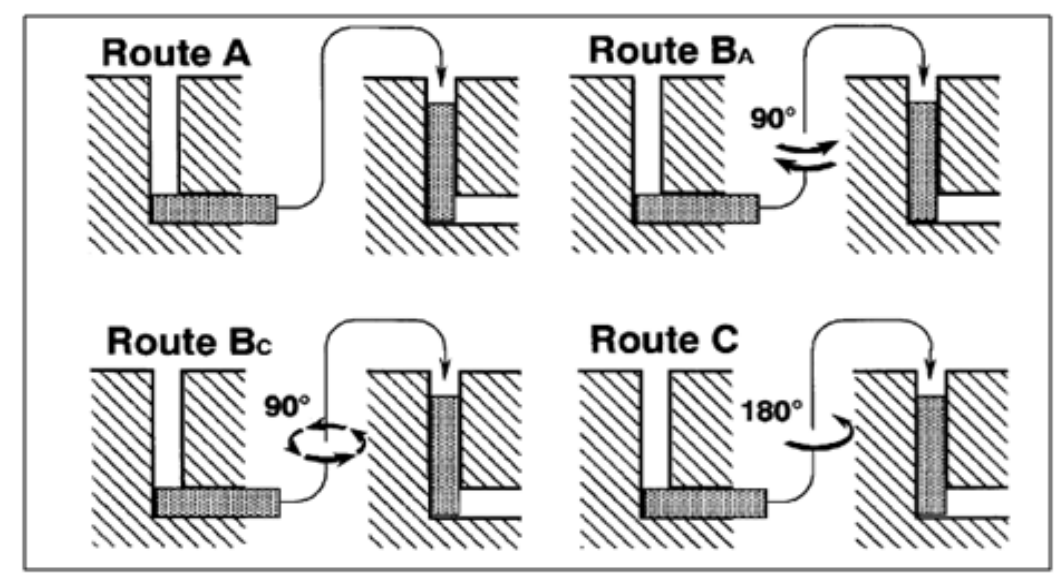

Figure3: processing routes of ECAP for Aluminum

Strong microstructure refinement by different ECAP process routes can quite easily be attained in various metallic materials. Fabrication of homogeneous UFG microstructures having high angle grain boundaries by ECAP is a complex problem since the number of passes and the selected ECAP route can be very important parameters of the processing. But to attain equiaxed grain refinement with maximum mechanical properties at least the sample has to be pressed for four passes so it can be achieved only through solution treated and annealed conditioned samples. 


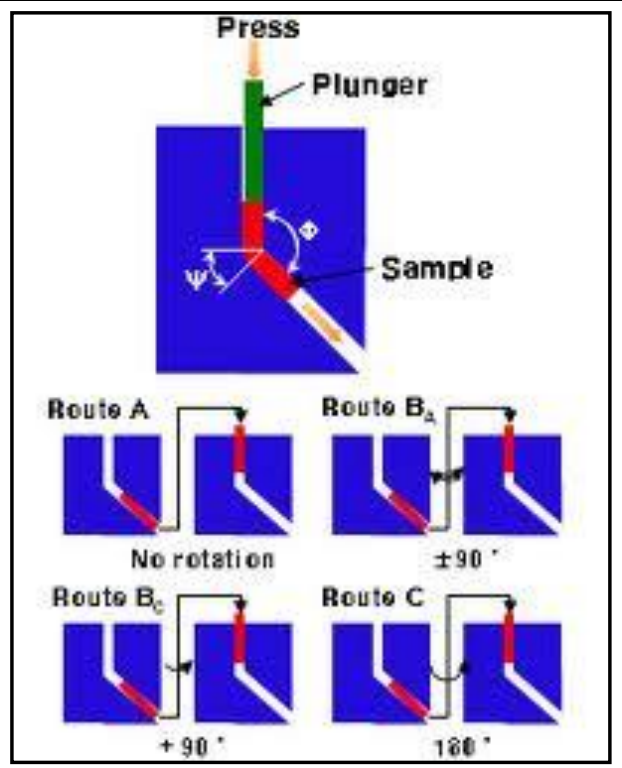

Figure4: processing routes of ECAP for magnesium

Figure 4 shows the various processing routes for magnesium available in ECAP. A single pass of ECAP introduces an inhomogeneous hardness distribution into the cross-section of the billet, especially adjacent to the bottom surface where the hardness is lower than in other positions. The large in-homogeneity is introduced in the first pass. It is apparent that the in-homogeneity is effectively reduced after four passes of ECAP. Thus the homogeneity improves through repetitive pressings. Some experiments have shown that the processing route has some effect on the mechanical and/or creep properties of the UFG materials.

\subsection{Processing Parameters of ECAP Process}

ECAP parameters greatly influence the final products. They are 1) Amount of deformation shear strain, 2) No. of passes, 3) Rotation angle between each repetitive pressing, 4) Strain monitored-an intense shear strain is therefore imposed as the sample passes through the shearing plane. 5) Preheat temperature in process. The main important parameters for fatigue crack propagation (FCP) are 6) critical cyclic $\left(\Delta \mathrm{K}_{\mathrm{th}}\right), \Delta \mathrm{K}_{\mathrm{th}}$ represents the cyclic load amplitude to establish a characteristic cyclic damage. 7) Critical maximum stress intensity $\left(K_{\max }\right), K_{\max }$ represents the peak load to break open the bonds in a cyclically damaged region 8) load ratio $\mathrm{R}=\mathrm{K}_{\min } / \mathrm{K}_{\max }$. Decrease in grain size gradually decreases the load ration sensitivity of $\Delta \mathrm{K}_{\text {th }}$ [7]. The ductility- optimized condition reveals superior FCP properties compared to the as-processed conditions.

\section{RESEARCH AND DEVELOPMENT USING ECAP}

\subsection{Pure Aluminum (Histogram: figures 5, 6)}

Pure Al. samples were processed by ECAP at room temperature for up to four passes using route $\mathrm{B}_{\mathrm{C}}$. According to some experiments, the micro hardness value for pure Al. is $43.2 \mathrm{HV}$ subjected to four passes of ECAP using the solid die with $\psi=20^{\circ}$. But the micro hardness value is $42.1 \mathrm{HV}$ for ECAP through four passes using the split die with $\psi=0^{\circ}$. By comparison the hardness value is $18 \mathrm{HV}$ for the samples in unpressed condition, thereby showing that the hardness value is increased on further ECAP process. The hardness value is increased due to the reduction in grain size from $1 \mathrm{~mm}$ to $1.3 \mu \mathrm{m}$ after four ECAP passes at $\Phi=90^{\circ}$ and $\psi=20^{\circ}$. The average hardness value for pure al. (99.99\%) is $40.5 \mathrm{HV}$ after one pass but the hardness value is increased to $43.6 \mathrm{HV}$ after four passes. In pure Al. there is saturation after the second pass then the hardness remains almost the same until eight passes. Some inhomogeneity is there in a small area in the vicinity of the bottom surfaces of the samples where the hardness value is lower than the average vale. This inhomogeneous area tends to cover a slightly larger fraction of the cross sectional surface in the sample pressed using the split die with $\psi=0^{\circ}$. The inhomogeneities observed at the lower surfaces of the billets are attributed to the development of a shearing zone during ECAP. In pure Al. the level of homogeneity is higher as compared with Al.6061 alloy and the number of required passes is lower. Pure Al. has very high stacking fault energy, a high strai $\mathrm{n}$ hardening rate and a rapid recovery; these are all materials properties, so that it is easy to obtain a high density of dislocations under a fixed applied strain and this favors the development of an 
equilibrium ultrafine grained configuration. Pure Al. reaches a straining saturation in a short period of time because there is no hardening mechanism for pure Al. except dislocation hardening. The earlier investigations on creep test about pure Al. show that the processing by ECAP of a coarse-grained high purity Al. give a potential for a marked improvement in the creep properties.

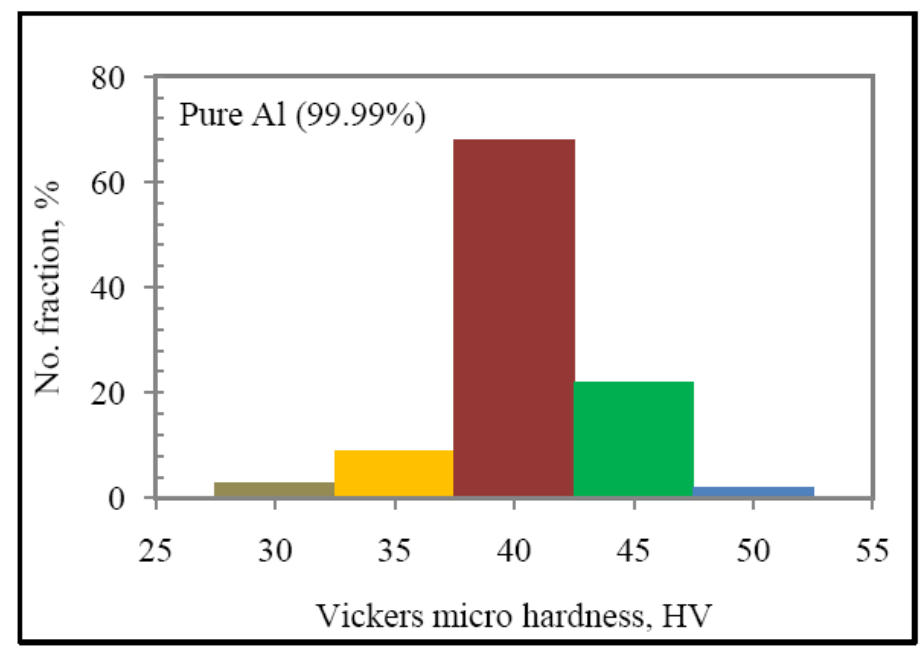

Figure5. Histogram, No. of Fraction Measured Value of HV, after 1 Pass at Room Temperature

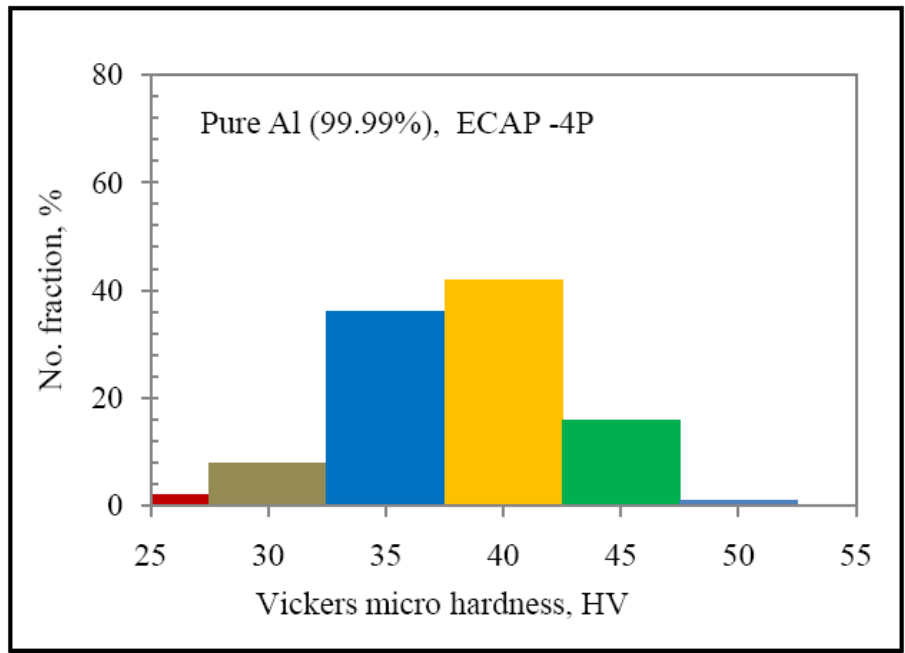

Figure6. Histogram, No. of Fraction Measured Value of HV, after 4 Passes at Room Temperature

\subsection{Al. 6061 alloy (Histogram: figures 7,8 )}

Alloy is processed by ECAP at room temperature up to a maximum of six passes using $\Phi=90^{\circ}$, $\psi=20^{\circ}$. The pressings are not extended beyond six passes to avoid cracking. Investigations showed, this material achieves a grain size of nearly $0.3 \mu \mathrm{m}$ during ECAP when pressing with an initial grain size of $50 \mu \mathrm{m}$. This material again exhibits excellent homogeneity in the unpressed condition with the hardness value of $45 \mathrm{HV}$. But after single pass the hardness value is increased to an average value of $78 \mathrm{HV}$. In the subsequent passes, the region having the low HV values occurs in the vicinity of the lower surface of the billet gradually reduces in size. Here the hardness continues to slowly increase throughout the entire cross-section even after six passes. This alloy has the hardness value of $78 \mathrm{HV}$ after single pass of ECAP, but after four passes the average hardness value is 95HV. Although the homogeneity of the micro hardness distribution increases slightly as the number of passes of ECAP increases from one to four, the improvement in the Al. 6061 alloy is much less than in pure Al. The hardness for the Al. 6061 alloy is not saturated after four passes of ECAP and therefore unlike the samples of pure Al, it is more difficult to establish an equilibrium microstructure in the Al.6061 alloy. Al.6061 has lower stacking fault energy, a lower strain hardening rate, a low rate of recovery. Alloying elements play a role in providing barriers in the form of precipitates for dislocation movement. Therefore a larger number of passes is required in the Al.6061 alloy in order to achieve a 


\section{S. Senthil Murugan}

saturation condition and the presence of precipitates provides additional hardening so that the alloy exhibits a relatively long region of strain hardening. Thus the alloy requires a larger strain in order to achieve an equilibrium array of ultrafine grains and therefore the development of homogeneity is slower than in pure Al. In alloys the homogeneity develops more slowly as compared to pure materials. Increasing number of passes is required in order to achieve stable and equilibrium microstructure when magnesium is added to aluminum in solid solution. It is possible to introduce UFG microstructures in technologically relevant alloys like age hardenable aluminum alloys.

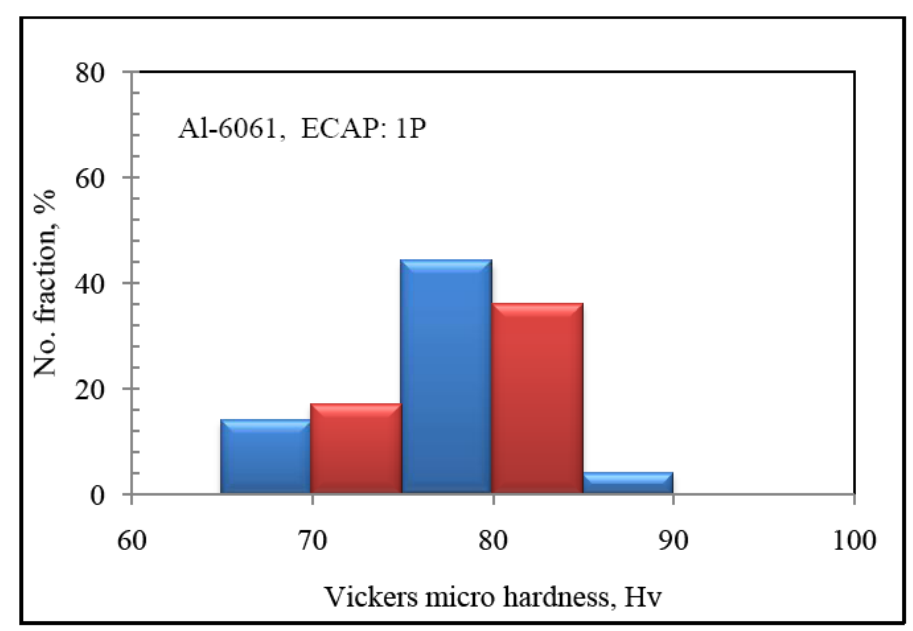

Figure7. Histogram, No. of Fraction Measured Value of HV, after 1 Pass at Room Temperature

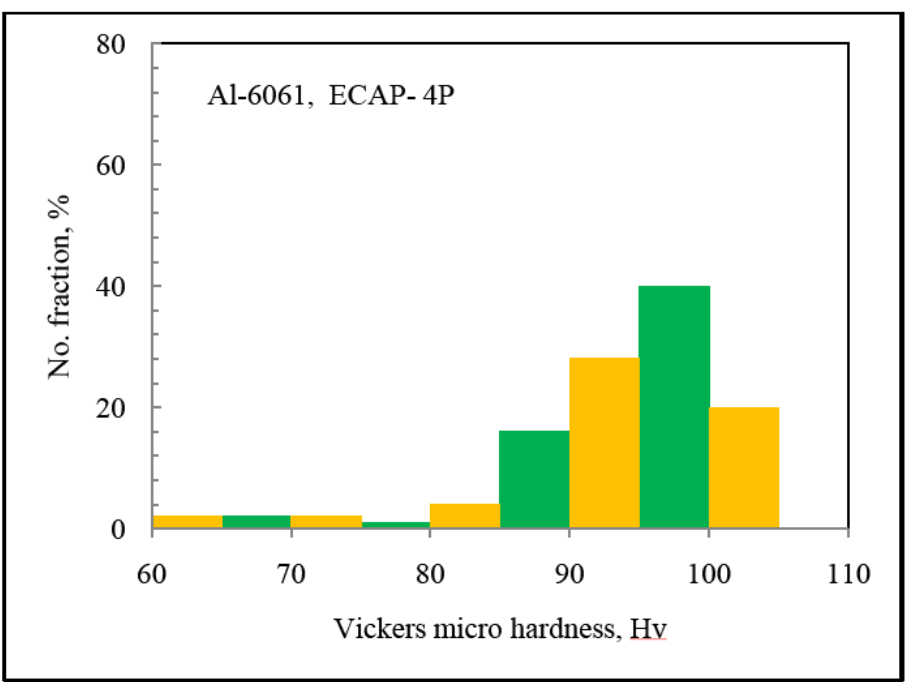

Figure8. Histogram, No. of Fraction Measured Value of HV, after 4 Passes at Room Temperature

The comparison of hardness value for pure $\mathrm{Al}$ and $6061 \mathrm{Al}$ is given in the Figure 9 and 10. These figures give the details after ECAP.

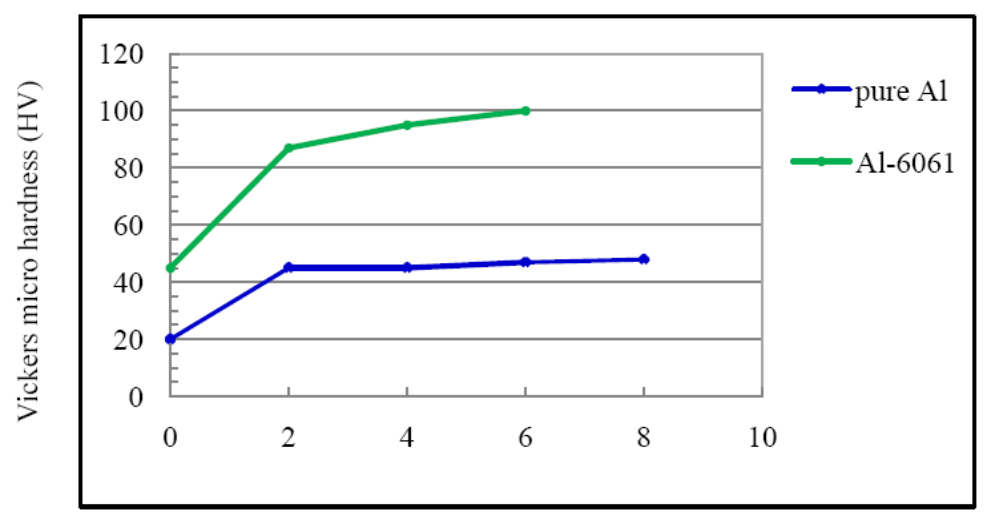

No. of passes

Figure9. $H V$ vs No. of Passes in ECAP for Pure Al and Al 6061 Pressed at Room Temp. Using Route $B_{C}$ 
Equal Channel Angular Pressing: A Novel Technique for the Production of Ultra Fine Grained Structure in Materials - A Mini Review

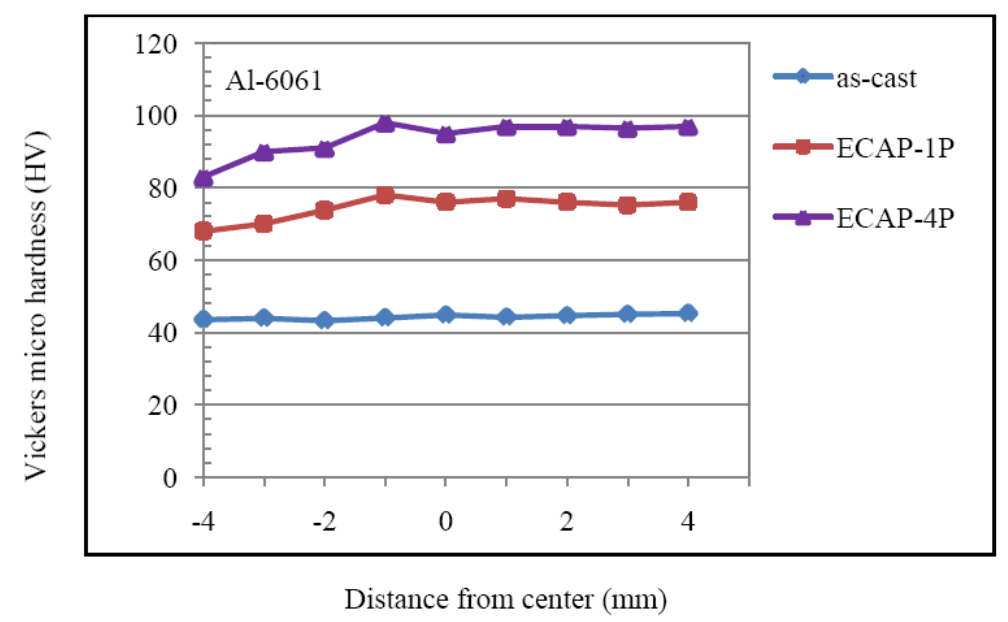

Figure10. Hardness Value of 6061 Al Recorded Along Z Direction

\subsection{Al. 6082 alloy}

ECAP processed samples of the Al.6082 alloy reference alloy showed a clear recrystallization peak at temperature $315-360^{\circ} \mathrm{C}$; whereas the Scandium containing alloy retained its ultra fine structure upto temperatures well exceeding $450^{\circ} \mathrm{C}$ [8]. Dispersoid -forming elements in Al. alloys is a widely recognized method to refine the as cast microstructure and to achieve a substantial resistance to recrystallization during hot working.

\subsection{Al-Mg-Si-Sc alloy}

Scandium (Sc) represents one of the most powerful elements resulting copious precipitation of coherent $\mathrm{Al}_{3} \mathrm{Sc}$ particles is able to retain the original deformed microstructure of the alloy even after high-temperature annealing [8]. Due to its effectiveness, restoration in Scandium containing alloys proceeds mainly by recovery it is very difficult to obtain a fully recrystallized microstructure. It is also well accepted that the effect of Scandium is amplified by the simultaneous presence of Zircon $(\mathrm{Zr})$ giving rise to the formation of complex $\mathrm{Al}_{3}\left(\mathrm{Sc}_{\mathrm{x}} \mathrm{Zr}_{\mathrm{x}}\right)$ precipitates. During the solidification, $\mathrm{Zr}$ tends to segregate to dendrite center whereas Sc to the last solid that means edges of the dendrites. Thus allowing a fairly homogeneous distribution of precipitates throughout the structure and avoiding the formation of precipitate- free zones that are prone to recrystallization. In addition, the precipitation kinetics of the $\mathrm{Al}_{3} \mathrm{Sc}$ phase is reported to be much faster than that of the $\mathrm{Al}_{3} \mathrm{Zr}$ thus leading to a rapid nucleation of dispersoids in the alloy structure. The diffusivity of Sc in Al. is also several orders of magnitude greater than $\mathrm{Zr}$, thus the coursing kinetics of the $\mathrm{Al}_{3} \mathrm{Sc}$ phase would encourage the use of a combination of $\mathrm{Sc}$ and $\mathrm{Zr}$ in order to properly balance these effects. It was also demonstrated that $\mathrm{Sc} / \mathrm{Zr}$ - modified Al. alloys can be refined to sub micrometer grain size levels by SPD that provides high thermal stability. The alloy contains precipitates that if refined to certain degree may act to aid in the stability of the UFG microstructure.

\subsection{Others}

Pure copper: Microstructural evolution is very slow in materials such as pure copper where the stacking fault energy is very low. Pure gold: The microstructure and mechanical properties of pure gold were examined after different number of equal channel angular pressing passes. The hardness and $0.2 \%$ proof stress from the compression tests were observed to increase only up to the fourth pass whereas the compressive strength at $40 \%$ strain kept increasing gradually with increasing the number of passes. Microstructure with low angle grain boundaries and shear bands were observed until the eighth pass and equiaxed grains with high angle grain boundaries were observed only after the twelfth pass [9]. Light alloy based composites: This so called paradox of strength and ductility is of great importance for future light weight construction materials.

\section{AdVANTAgeS AND DisAdVANTAges OF ECAP}

Advantages: A dominant SPD process is ECAP [10]. It is a simple processing technique that has the capacity of being developed into a continuous processing procedure. ECAP process breaks down and refines second phases or particles under high pressure. Such refined second phases, precipitates or particles may act to stabilize the UFG structure and provide more resistance to undesired grain 


\section{S. Senthil Murugan}

growth. When using the ECAP process, it has the potential for producing large bulk samples sufficient for industrial applications without the introduction of any porosity or contaminants. In ECAP process, billet has nearly the same size and shape before and after deformation, and very large strains are introduced in bulk material by simple shear as the billet is forced through the intersection of the die channels. Multiple passes through the die are possible without any reduction in cross-sectional area. It can be scaled upto produce relatively large bulk samples. Strain in ECAP extruded materials is accumulated with increasing number of passes.

Disadvantages: It is hard to achieve a work piece of arbitrary cross section in ECAP process. It is impossible to obtain products with inner channels in ECAP process. The samples after four pressings were brittle and easy to crack in the further pressing. Thus, the short anneal followed by ECA pressing is necessary for repeating pressing [11].

\section{Applications}

ECAP process is applied in the fabrication of MEMS components (micro heat exchangers) using ultra fine grained aluminium alloys. Embossing of ECAP processed UFG aluminium alloys has shown a good potential for application in micro device fabrication and optical components. Ultra fine grained materials produced by ECAP are mainly used in the production of Structural components, Bio medical and electronic products.

\section{CONClusion}

Equal-channel angular pressing (ECAP) technique has been proven to be very useful in improving strength of ingot-processed metallic alloys through grain refinement. Strong microstructure refinement by ECAP procedure can quite easily be attained in various metallic materials. It is necessary to process materials by ECAP up to multiple passes in order to achieve satisfactory ultrafine-grained microstructure. In pure Al. the level of homogeneity is higher as compared with Al.6061 alloy and the number of required passes is lower. In alloys the homogeneity develops more slowly as compared to pure materials. Materials produced by SPD techniques can be tailored to have both superior performance and properties.

\section{ACKNOWLEDGEMENTS}

The author would like to thank Dr. T.P.D.Rajan, Senior Scientist, National Institute for Interdisciplinary Science and Technology, Trivandrum- 695019, for providing a basic knowledge on ECAP.

\section{REFERENCES}

[1] Aferdita Vevecka- Priftaj, Andreas Bohner, "Strain rate sensitivity of ultrafine grained aluminum alloy AA6061" Mat. Sci. Forum vol. 584-586 (2008) pp.741-747

[2] Ruslan Z Valiev"Superplastic behavior of nano crystalline metallic materials" Mat. Sci. Forum vol.243-245 (1997) pp.207-216

[3] George Chi Ho Tang, Mark Hoffman,"Fatigue crack growth in ultra fine grained Aluminum alloy" Mat. Sci. Forum vol. 690 (2011) pp.254-257

[4] Cheng Xu. Terence G. Langdon "the development of hardness homogeneity in aluminum and an aluminum alloy processed by ECAP” J. Mater Sci. (2007) 42:1542-1550

[5] Sklenicka V, Dvorak J "effect of equal channel angular pressing (ECAP) on creep in aluminum alloys" Mat. Sci. Forum vol.539-543 (2007) pp.2904-2909

[6] Sklenicka V, Dvorak J "Effect of processing route on microstructure and mechanical behavior of ultrafine grained metals processed by severe plastic deformation" Mat. Sci. Forum vol. 482 (2005) pp.83-88

[7] Houkauf k, Halle T, "Near- threshold fatigue crack propagation in an ECAP-processed ultrafinegrained aluminum alloy" Mat. Sci. Forum vol. 667-669 (2011) pp.873-878

[8] Angella G, BassaniP, "microstructure evolution and kinetics of Al-Mg-Si and Al-Mg-Si-Sc alloys processed by ECAP” Mat. Sci. Forum vol. 503-504 (2006) pp.493-498

[9] Nagasekhar AV, Rajkumar T, Stephan D, Tick-Hon Y and Guduru RK "Microstructure and mechanical properties of pure gold processed by equal channel angular pressing" Mat. Sci. and Engineering a-Structural Materials Properties Microstructure and Processing, 524 1-2: 204-207, 2009. 
[10] Andrzej Rosochowski, University of Strathclyde, Glasgow, UK, PPT Source on "Metal forming technology for nanostructuring of light alloys".

[11] L.J. Zhenga, C.Q. Chena, T.T. Zhoua, P.Y. Liua, M.G. Zengb, Structure and properties of ultrafine-grained Al-Zn-Mg-Cuand Al-Cu-Mg-Mn alloys fabricated by ECA pressing combined with thermal treatment, Elsevier, 2003.

\section{AUTHOR's BIOGRAPHY}

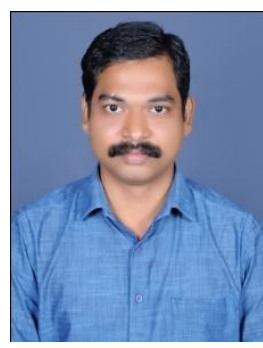

S. Senthil Murugan, is currently working as Assistant Professor in the Department of Mechanical Engineering, Mepco Schlenk Engineering College Sivakasi and doing Ph.D at NIT, Trichy. He has published around 25 research articles in conferences and journals. He guided more than 10 PG degree students. He has undergone summer faculty research fellowship at IIT Delhi. He is involving in two govt. funded (MSME) projects. He is the member of Indian Institute of Metals and Indian of Society for Technical Education. Area of interests is welding, metal matrix composite environmental safety etc... 